Pontifícia Universidade C $_{\text {atólica }}$

Felipe Bernardo Estre

\title{
Poder, Interdependência e Desigualdade
}

Dissertação de Mestrado

Dissertação apresentada ao Programa de Pósgraduação em Relações Internacionais da PUC-Rio como requisito parcial para obtenção do grau de Mestre em Relações Internacionais.

Orientador: Paulo Luiz Moreaux Lavigne Esteves 


\section{Pontifícia Universidade C $_{\text {atólica }}$ \\ DO RIO DE JANEIRO}

Felipe Bernardo Estre

Poder, Interdependência e Desigualdade

Dissertação de Mestrado

Dissertação apresentada como requisito parcial para obtenção do título de Mestre pelo programa de Pósgraduação em Relações Internacionais da PUC-Rio. Aprovada pela Comissão Examinadora abaixo assinada.

Prof. Paulo Luiz Moreaux Lavigne Esteves

Orientador

Instituto de Relações Internacionais - PUC-Rio

Prof. a Monica Herz Instituto de Relações Internacionais - PUC-Rio

Prof. a Rossana Rocha Reis Departamento de Ciência Política - USP

Prof .. Monica Herz

Coordenadora Setorial do Centro de Ciência Sociais - PUC-Rio

Rio de Janeiro, 17 de outubro de 2011. 
Todos os direitos reservados. É proibida a reprodução total ou parcial do trabalho sem autorização da Universidade, do autor e do orientador.

Felipe Bernardo Estre

Graduou-se em Relações Internacionais pela Universidade de São Paulo em 2008.

Ficha Catalográfica

Estre, Felipe Bernardo

Poder, interdependência e desigualdade / Felipe Bernardo Estre; orientador: Paulo Luiz Moreaux Lavigne Esteves. -2011.

90 f. ; $30 \mathrm{~cm}$

Dissertação (mestrado) - Pontifícia Universidade Católica do Rio de Janeiro, Instituto de Relações Internacionais, 2011.

Inclui bibliografia.

1. Relações internacionais - Teses. 2. Interdependência. 3. Desigualdade. 4. Ordem internacional. I. Esteves, Paulo Luiz Moreaux Lavigne. II. Pontifícia Universidade Católica do Rio de Janeiro. Instituto de Relações Internacionais. III. Título. 
Para meus irmãos, Guilherme e Victor. 


\section{Agradecimentos}

O solitário e exaustivo processo de escrever esta dissertação certamente estaria ameaçado sem as pessoas maravilhosas que estiveram ao meu lado.

À minha família, pela compreensão, apoio e amor incondicionais.

À família que eu pude escolher, Thiago Carreira, Bruna Vilela e Heloisa Barrozo, pelo carinho, amor, paciência, conversas, risadas, e por serem uma fonte absolutamente inesgotável de bons momentos.

Ao meu orientador e professor Paulo Esteves pela genialidade, confiança e por ter guiado meus passos nessa árdua tarefa de escrever uma dissertação.

Aos meus companheiros de pós-graduação, irmãos de caminhada, que tornaram minha estada no Rio de Janeiro bem mais alegre, agradável e estimulante.

Aos professores do Instituto de Relações Internacionais da PUC-Rio por seus valiosos ensinamentos e constante interesse em nosso crescimento acadêmico e intelectual, dentre os quais destaco Nizar Messari (cujo brilhantismo e sensibilidade me inspiram profunda admiração) e Monica Herz (pelas portas que nos abriu ao nos fazer pensar sobre o Conhecimento).

Aos professores do Instituto de Relações Internacionais da USP, junto dos quais dei meus primeiros passos na vida acadêmica, em especial Rossana Reis (pela amizade e valiosos conselhos acadêmicos e pessoais) e Rafael Villa (por me apresentar outros caminhos nas teorias de Relações Internacionais). 
Aos meus irmãos da vida, Ana Maria Araujo, Natalia Governatore, José Osmar e Fernando Governatore, que sempre estiveram ao meu lado a despeito da distância física.

Aos funcionários do Instituto de Relações Internacionais por sua acessibilidade e incansável disposição em ajudar-nos.

Ao Conselho Nacional de Desenvolvimento Científico e Tecnológico e à Pontifícia Universidade Católica do Rio de Janeiro pelos auxílios concedidos, sem os quais este trabalho não poderia ter sido realizado. 


\section{Resumo}

Estre, Felipe Bernardo; Esteves, Paulo Luiz Moreaux Lavigne. Poder, Interdependência e Desigualdade. Rio de Janeiro, 2011. 90p. Dissertação de Mestrado - Instituto de Relações Internacionais, Pontifícia Universidade Católica do Rio de Janeiro.

A dissertação pretende repensar a desigualdade nas Relações Internacionais a partir da obra Power and Interdependence, publicada em 1977 por Robert Keohane e Joseph Nye. Argumenta-se que, ao contrário do que os autores afirmam, os novos processos políticos que caracterizam a política internacional desde o início do século XX não necessariamente resultaram na diminuição da hierarquia no sistema internacional. Pelo contrário, as organizações internacionais permitem a articulação de outras formas de discriminação entre os Estados que não podem ser resumidas a fatores econômicos ou assimetrias de poder. O cerne discussão sobre a desigualdade na obra de Keohane e Nye está no próprio conceito de interdependência complexa, o qual divide o sistema internacional entre os "avançados" ou "pluralistas e industrializados", e aqueles que não podem fazer parte desse grupo sem os devidos ajustes. As organizações internacionais, portanto, não seriam fatores que diminuiriam a hierarquia no sistema internacional, mas seriam reprodutoras da desigualdade por meio da atribuição de organizationally dependent capabilities.

\section{Palavras-chave}

Interdependência; desigualdade; ordem internacional. 


\section{Abstract}

Estre, Felipe Bernardo; Esteves, Paulo Luiz Moreaux Lavigne (Advisor). Power, Interdependence and Inequality. Rio de Janeiro, 2011. 90p. MSc. Dissertation - Instituto de Relações Internacionais, Pontifícia Universidade Católica do Rio de Janeiro.

The dissertation intends to rethink the inequality in International Relations based on the book Power and Interdependence, published in 1977 by Robert Keohane and Joseph Nye. It is argued that, contrary to what the authors say, the new political processes that characterize international politics since the beginning of the twentieth century did not resulted necessarily in the decrease of international hierarchy. On the contrary, international organizations allow the articulation of other forms of discrimination among the states that cannot be reduced to economic factors or asymmetries of power. The core discussion about inequality in the work of Keohane and Nye is on the very concept of complex interdependence, which divides the international system between the "advanced" or "pluralistic, industrialized," and those that cannot join this group without the proper adjustments. Therefore, international organizations would not be factors that decrease the hierarchy in the international system, but are reproducing inequality through the allocation of organizationally dependent capabilities.

\section{Keywords}

Interdependence; inequality; international order. 


\section{Sumário}

1. Introdução 12

2. Poder e Interdependência 19

$\begin{array}{ll}\text { 2.1. O interlocutor: Realismo } & 20\end{array}$

2.2. Interdependência 22

2.3. Poder 25

2.4. Regimes internacionais $\quad 30$

2.5. Interdependência complexa 39

3. Ordem Internacional e Hierarquia 43

3.1. A questão da Ordem 44

3.2. A ordem internacional de Power and Interdependence 46

3.3. Implicações normativas

3.4. Hierarquia organizacional $\quad 58$

4. Poder, Interdependência e Desigualdade 63

4.1. Hierarquia e desigualdade $\quad 64$

$\begin{array}{ll}\text { 4.2. Dupla desigualdade } & 67\end{array}$

$\begin{array}{ll}\text { 4.3. Ordem e desigualdade } & 70\end{array}$

4.4. A força a favor da ordem internacional 73

$\begin{array}{lr}\text { 5. Conclusão } & 80\end{array}$

6. Bibliografia $\quad 85$ 


\section{Lista de figuras}

Figura 1: Interdependência assimétrica e seus usos 29

Figura 2: Modelos estruturais de mudança de regime 35

Figura 3: Modelo da organização internacional 38

Figura 4: Poder explicativo - overall structure e economic process 61 
Conceptions of order...are always accompanied by the self interpretation of that order as meaningful...that is about the particular meaning that order has. In this sense, self interpretation is always part... of the reality of order, of political order, or, as we might say, of history.

Eric Voeglin

\section{A Casa da História.}

Com o chão de pedra fresca e paredes escuras, e sombras ondulantes enfileiradas lado a lado. Lagartos gordos, translúcidos, viviam atrás dos velhos quadros, $e$ ancestrais pálidos, esfarelantes, com unhas dos pés duras, e hálito cheirando a mapas amarelados, murmuravam em sussurros sibilantes, como papel.

"Mas nós não podemos entrar", Chacko explicou, "porque fomos trancados do lado de fora. E quando olhamos para dentro das janelas, tudo o que vemos são sombras. E quando tentamos ouvir, tudo o que ouvimos é um murmúrio”.

Arundhati Roy, O Deus das Pequenas Coisas 